\title{
Quality of life of patients with brucellosis in an endemic area of Mexico
}

\author{
Guillermina García-Juárez $z^{1,2}$, J. Efrén Ramírez-Bribiesca ${ }^{1^{*}}$, Luz M. Hernández-Calva², \\ José D. Vázquez-Vázquez ${ }^{1}$, Alfonso Pérez-Sánchez ${ }^{1}$, Christine M. Budke ${ }^{3}$ \\ ${ }^{1}$ El Colegio de Tlaxcala AC, San Pablo Apetatitlán, Tlaxcala, México; ${ }^{*}$ Corresponding Author: ramirezbribiesca@hotmail.com \\ ${ }^{2}$ Facultad de Agrobiología, Universidad Autónoma de Tlaxcala, Tlaxcala, México \\ ${ }^{3}$ College of Veterinary Medicine and Biomedical Science, Texas A\&M University, College Station, USA
}

Received 22 July 2012; revised 20 August 2012; accepted 3 September 2012

\begin{abstract}
The aim of this study was to evaluate the quality of life of patients infected with brucellosis compared to a control population from the same geographic region. The quality of life of brucellosis positive and brucellosis negative individuals from rural and urban areas of Mexico was evaluated using the Short-Form SF-36 Health Survey. This survey is a generic measure of physical and mental health-related quality of life. Data analysis was performed using one-way analysis of variance and the Tukey test. Brucellosis patients had lower overall quality of life compared with the controls. Brucellosis patients from rural areas had lower overall quality of life $(P<0.05)$ compared with brucellosis patients from urban areas. In conclusion, human brucellosis affects quality of life, with patients living in rural areas most severely impacted. This may be due to the lack of local public policies and programs for the prevention, diagnosis, and treatment of brucellosis.
\end{abstract}

Keywords: Brucellosis; Quality of Life

\section{INTRODUCTION}

Brucellosis is an infection of animals and humans that occurs worldwide, with endemic areas located in Latin America, including Mexico. This zoonotic disease is especially prevalent in rural agricultural regions and is caused by the bacteria Brucella spp. Species that cause the most severe human illness are B. melitensis, $B$. suis, and $B$. abortus. In addition, due to the highly infectious nature of these species and their ability to be readily aerosolized, these pathogens are listed as potential bioweapons by the Centers for Disease Control and Prevention (CDC) in the USA. According to the World Organi- sation for Animal Health (OIE), brucellosis is a reportable zoonosis, with considerable socioeconomic, public health, and international-trade implications [1]. In places where brucellosis is endemic, humans can become infected via contact with infected animals or consumption of unpasteurized milk and milk products from the infected cows and goats [2].

Brucellosis is a disease, which is believed to have a significant impact on quality of life [3]. Clinical manifestations associated with brucellosis include undulant fever, which is characterized by a body temperature that can vary from $37^{\circ} \mathrm{C}$ to $40^{\circ} \mathrm{C}$, night sweats, chills and weakness. Other common symptoms include malaise, insomnia, anorexia, headache, arthralgia, constipation, sexual impotence, nervousness and depression. Human brucellosis can also affect various internal organs, with symptoms dependent on the site of infection, such as encephalitis, meningitis, spondylitis, arthritis, endocarditis, orchitis, and prostatitis $[4,5]$.

Due to local traditions and customs, as well as a lack of prevention and eradication programs by health units in rural and urban territories, brucellosis has not been well controlled in most Latin American countries. The condition is especially common in rural communities where farmers manufacture cheese using unpasteurized milk, including most rural areas in Mexico where people engage in small-holder subsistence agriculture. Control of brucellosis is complex and involves social, economic, and political factors [6]. It is believed that the lack of brucellosis control programs in these countries results in a decreased quality of life and a decreased ability for infected individuals to work, thereby affecting the region's economy $[7,8]$. Questionnaires designed to measure general quality of life, such as the Short-Form 36 (SF-36), can be used to compare relative disease burden among populations [9]. The aim of this study was to investigate the differential impact of brucellosis on the quality of life of patients in an affected rural and urban territory in the state of Tlaxcala, Mexico. 


\section{MATERIAL AND METHODS}

\subsection{Study Area}

Tlaxcala is located in central-eastern Mexico between $97^{\circ} 37^{\prime} 07^{\prime \prime}$ and $98^{\circ} 42^{\prime} 51^{\prime \prime}$ west longitude and $19^{\circ} 05^{\prime} 43^{\prime \prime}$ and $19^{\circ} 44^{\prime} 07^{\prime \prime}$ north latitude, with an area of $3987.94 \mathrm{~km}^{2}$, representing $0.2 \%$ of Mexico. The state has a population density of 267.8 inhabitants per $\mathrm{km}^{2}$ [10]. In Tlaxcala, $78 \%$ of the population is located in urban areas and $22 \%$ in rural areas [11]. Half of the population lives with some degree of poverty; based on housing conditions, access to health services, and availability of food as reported by Mexico’s National Population Council (CONAPO) [11]. Rural communities have a large population of goats and cows involved in the production of milk and unpasteurized milk products, including cheese. Fresh, unpasteurized cheese is sold in urban areas and has the potential to transmit brucellosis [12].

\subsection{Study Subjects}

The health sector of the state of Tlaxcala has a medical clinic that diagnoses zoonotic diseases and provides medical treatment for these diseases. The clinic keeps records indicating the number of people who test positive for brucellosis each year. The diagnosis is made taking into account medical history as well as clinical signs. Cases arising suspicion are confirmed by a blood agglutination test, performed following published guidelines [13]. Brucellosis patients of both sexes identified during 2010 and meeting the following criteria were eligible to participate in the study: 1) persons over 20 years of age, 2) who contributed to the upkeep of the household, and 3) who lived with a spouse or partner. Patients were selected from both rural and urban settings based on classifications defined by Trivelli et al. [14]. Urban patients were selected from the state capital and rural patients were selected from the community of Huamantla, which has the highest density of goats and cows in the state.

A control group was selected from the same urban and rural locations. Trained interviewers and a physician went door-to-door to identify the control population. In addition to the criteria used to select the brucellosis cases, controls had to meet the following criteria to be eligible to participate: 1) based on a medical history taken by the physician, the individual was not found to suffer from a chronic degenerative disease (for example, muscle and joint pains for more than a year's duration), 2) the individual had to consent to a blood agglutination test for brucellosis and receive a negative test result, and 3) the individual had to report consuming dairy products at least 2 times per week. Identified patients and controls were visited in their homes and the objectives of the study explained in detail. Upon agreement to participate in the study, individuals completed the Short-Form 36 (SF-36) quality of life survey. Due to the low literacy rate locally, the survey was read to participants by a trained interviewer who then filled in the provided answers. The final study population was composed of 88 individuals from 20 - 45 years of age (48 men and 40 women). Study groups were classified as: A) positive for brucellosis in a rural setting, $n=23$; B) negative for brucellosis in a rural setting, $n=21$; C) positive for brucellosis in an urban setting, $n=23$; D) negative for brucellosis in an urban setting, $\mathrm{n}=21$.

\subsection{Quality of Life}

The Short-Form 36 (SF-36) [15] is a 36 question generic quality of life survey that was developed by the Health Institute, New England Medical Center, Boston, Massachusetts and has been applied and validated by the World Health Organization [16]. The version used in this study was adapted to the Mexican population by Alonso et al. (1995) [17] and translated into Spanish as per Ayuso Mateos et al. (1999) [18]. Domains of health measured by the SF-36 can be found in Table 1 .

\subsection{Statistical Analysis}

Questions making up each of the eight health domains were scored and coded, summed, and transformed to a scale ranging from 0 (worst health status) to 100 (best health status). All variables were found to be normally distributed according to the Shapiro-Wilk test. Therefore, the data were analyzed using one-way analysis of variance (ANOVA). Comparisons of means were conducted using the Tukey test. A P value of 0.05 or less was considered statistically significant. All data were analysed using the Statistical Package for the Social Sciences (SPSS) program version 15 [19].

\subsection{Ethics Approval}

Ethics approval for this study was obtained from the Secretaria de Salud, Tlaxcala, Mexico.

\section{RESULTS}

Table 2 shows the mean domain scores for brucellosis patients and controls in rural and urban areas. Role Emotional and Role Physical had the highest mean values in all groups and General Health and Vitality had the lowest values. There were no differences in quality of life between men and women for brucellosis patients or controls. Mean scores for all domains were significantly different between brucellosis patients and controls in both urban and rural areas $(\mathrm{P}<0.05)$. In addition, brucellosis patients from the rural community had significantly 
Table 1. Domains of health incorporated into the Short-Form 36 (SF-36) quality of life survey.

\begin{tabular}{|c|c|}
\hline 1) Physical Functioning (10 items) & $\begin{array}{l}\text { Defined as the degree of limitation for physical activity such as self-care, walking, } \\
\text { climbing stairs, stoop, gripping or carrying weights, moderate and intense efforts. }\end{array}$ \\
\hline 2) Role Physical (4 items) & $\begin{array}{l}\text { Defined as the degree to which physical health interferes with work and other daily } \\
\text { activities including performance than desired, limiting the type of activities undertaken } \\
\text { or difficulty in implementation of activities. }\end{array}$ \\
\hline 3) Bodiy pain (2 items) & It refers to the intensity of pain and its effect on normal work, both outdoors and at home. \\
\hline 4) General Health (5 items) & $\begin{array}{l}\text { Defined as personal health assessment that includes current health, the prospects } \\
\text { for future health and resistance to illness. }\end{array}$ \\
\hline 5) Vitality (4 items) & Defined as a feeling of energy and vitality, compared to the feeling of tiredness and exhaustion. \\
\hline 6) Social Functioning (2 items) & It is the perceptions of the issues of physical or emotional health interfere with normal social life. \\
\hline 7) Role Emotional (3 items) & It is the degree of emotional problems that are associated with work or other daily activities. \\
\hline 8) Mental Health (5 items) & This dimension includes depression, anxiety behavior management or general welfare. \\
\hline
\end{tabular}

Table 2. Mean scores for quality of life domains obtained in the studied territories ${ }^{1}$.

\begin{tabular}{|c|c|c|c|c|c|c|c|}
\hline & \multicolumn{2}{|c|}{ Rural territory } & \multicolumn{2}{|c|}{ Urban territory $^{2}$} & \multicolumn{2}{|c|}{ Main effects ${ }^{3}$} & \multirow[b]{2}{*}{ SEM } \\
\hline & $\begin{array}{c}\text { Brucellosis } \\
\text { Positive }\end{array}$ & $\begin{array}{l}\text { Brucellosis } \\
\text { Negative }\end{array}$ & $\begin{array}{l}\text { Brucellosis } \\
\text { Positive }\end{array}$ & $\begin{array}{l}\text { Brucellosis } \\
\text { Negative }\end{array}$ & $\begin{array}{l}\text { Brucellosis } \\
\text { Positive }\end{array}$ & $\begin{array}{c}\text { Brucellosis } \\
\text { Negative }\end{array}$ & \\
\hline 1) Physical Functioning & $78.78^{\mathrm{a}}$ & $95.34^{\mathrm{b}}$ & $74.15^{\mathrm{a}}$ & $92.91^{\mathrm{b}}$ & $76.46^{\mathrm{a}}$ & $94.13^{\mathrm{b}}$ & 2.4 \\
\hline 2) Role Physical & $77.27^{\mathrm{a}}$ & $97.72^{\mathrm{b}}$ & $82.81^{\mathrm{ac}}$ & $93.75^{\mathrm{c}}$ & $80.04^{\mathrm{ac}}$ & $95.73^{\mathrm{c}}$ & 1.6 \\
\hline 3) Bodily Pain & $69.39^{\mathrm{a}}$ & $87.87^{\mathrm{b}}$ & $71.87^{\mathrm{a}}$ & $83.75^{\mathrm{b}}$ & $70.63^{\mathrm{a}}$ & $85.81^{b}$ & 2.3 \\
\hline 4) General Health & $56.60^{\mathrm{a}}$ & $71.03^{\mathrm{b}}$ & $59.75^{\mathrm{a}}$ & $67.50^{\mathrm{b}}$ & $58.18^{\mathrm{a}}$ & $69.27^{\mathrm{b}}$ & 2.1 \\
\hline 5) Vitality & $59.82^{\mathrm{a}}$ & $73.20^{\mathrm{b}}$ & $62.73^{\mathrm{a}}$ & $80.17^{\mathrm{b}}$ & $61.28^{\mathrm{a}}$ & $76.70^{\mathrm{b}}$ & 2.1 \\
\hline 6) Social Functioning & $72.42^{\mathrm{a}}$ & $87.27^{\mathrm{b}}$ & $71.25^{\mathrm{a}}$ & $85.00^{\mathrm{b}}$ & $71.83^{\mathrm{a}}$ & 86.14 & 1.7 \\
\hline 7) Role Emotional & $80.30^{\mathrm{a}}$ & $90.40^{\mathrm{b}}$ & $88.54^{\mathrm{a}}$ & $90.62^{\mathrm{b}}$ & $84.54^{\mathrm{a}}$ & $90.51^{\mathrm{b}}$ & 1.5 \\
\hline 8) Mental Health & $64.82^{\mathrm{a}}$ & $73.80^{\mathrm{b}}$ & $67.89^{\mathrm{a}}$ & $75.0^{\mathrm{b}}$ & $66.36^{\mathrm{a}}$ & $74.4^{\mathrm{b}}$ & 1.9 \\
\hline
\end{tabular}

${ }^{1}$ Scale of 1 - 100; ${ }^{2}$ Different letters among the four groups in the same row show significant differences $(\mathrm{P}<0.05)$; ${ }^{3}$ Different letters between brucellosis negative and brucellosis positive groups in the same line of principal components show significant differences $(\mathrm{P}<0.05)$; SEM = Standard error mean.

lower scores in all domains compared to brucellosis patients from the urban study area $(\mathrm{P}<0.05)$.

\section{DISCUSSION}

In Mexico, the proportion of people relying on livestock for some or all of their livelihoods is high, ranging from $20 \%$ to over $60 \%$, depending on the livestock production system and region. In both pastoral and mixed agricultural/pastoral systems, people live closely with livestock populations that have a high prevalence of brucellosis, making these individuals at higher risk of infection. Brucellosis is known to have a great impact on economic development [20], both in terms of direct losses (morbidity, mortality) and indirect losses, including costs associated with ineffective control measures [21]. However, this is the first study to evaluate quality of life of patients with brucellosis compared to a control population.

Quality of life studies have been conducted for other diseases, including allergic diseases, such as asthma, and chronic obstructive pulmonary disease (COPD). In the current study, the General Health domain had the lowest mean value in the group of patients with brucellosis (56.60 for patients in the rural area and 59.75 for patients in the urban area). Comparatively, Martinez (2007) [22], reported a mean of 49.2, for this domain, in Mexican patients with allergic diseases, while Galicia (2008) [23] reported that Mexican patients with COPD had a mean value of 61.9 [24]. The General Health domain reflects an individual's perceptions of his or her general health status. Disease, such as brucellosis, can result in poor physical activity, an increasingly sedentary lifestyle, depression, and dependency on others. When these factors are combined with poor socioeconomic status and lack of insurance, this can result in an even more negative perception of current and future health.

The Vitality domain had the next lowest scores for brucellosis patients (59.92 for patients in the rural area 
and 62.73 for patients in the urban area). In patients with asthma with allergic rhinitis and COPD, mean values of 52.6 [24] and 50.2 [25,26] were reported, respectively. Low values for all three conditions could be attributed to the long duration and severity of the clinical manifestations associated with these conditions. Brucellosis is known to be associated with clinical signs such as night sweats, weakness, malaise, irritability, and depression, which can all contribute to a lack of energy [27].

Martinez (2007) [22] showed that patients with allergic diseases had a mean score of 62.7 for the Bodily Pain domain and Galicia (2008) [23] reported that patients with COPD had a mean score of 42.1 for this domain. Scores for the patients with allergic diseases and COPD were both lower than the values obtained for brucellosis patients in this study (69.39 in the rural population and 71.87 in the urban population). The difference was most likely due to allergic diseases and COPD causing more severe damage to a vital organ system (the lungs) and, therefore, having a greater impact on this aspect of quality of life. The Role Emotional variable had means greater than 80 for brucellosis patients in both rural and urban areas. A study in Havana, Cuba by Castillo et al. (2008) [28], found that the emotional status of people with chronic degenerative diseases was enhanced with the help of a supportive family, healthcare team and community. This may also be true for patients with brucellosis.

In Mexico, brucellosis continues to be a problem due to certain traditions and customs associated with food preparation and a lack of health programs designed to teach people about the safety concerns associated with living and working closely with livestock. Much of the rural population of Mexico has a low economic status, with many families now relying on funds sent from family members who have immigrated to other countries, such as the United States. Differences in quality of life between rural and urban area patients are most likely due to the additional socio-economic hardships that the rural population must endure. The results of this study indicate that brucellosis does appear to negatively impact the welfare and quality of life of patients and that this disease has the largest impact on those least equipped to handle additional stress and poor health. The data presented here reinforce the hypothesis that socioeconomics can impact quality of life associated with a certain disease or condition and that those most affected are often times individuals living in territories that are behind in their development of health and disease prevention strategies [5]. This necessitates the need for better education and public health programs aimed at these high risk populations.

\section{CONCLUSION}

The results of this study indicate that rural populations in Mexico are more vulnerable to decreases in quality of life due to brucellosis compared to urban populations. Education and outreach programs focusing on livestock associated zoonoses, including brucellosis, need to be enhanced, in these rural areas, to improve local public health and quality of life.

\section{REFERENCES}

[1] Godfroid, J., Scholz, H. C., Barbier, T., Nicolas, C., Wattiau, P., Fretin, D., Whatmore, A. M., Cloeckaert, A., Blasco, J. M., Moriyon, I., Saegerman, C., Muma, J. B., Dahouk, S., Neubauer, H. and Letesson, J. J. (2011) Brucellosis at the animal/ecosystem/human interface at the beginning of the 21st century. Preventive Veterinary Medicine, 102, 118-131. doi:10.1016/j.prevetmed.2011.04.007

[2] Seleem, M. N., Boyle, S. M. and Sriranganathan, N. (2010) Brucellosis: A re-emerging zoonosis. Review. Veterinary Microbiology, 140, 392-398. doi:10.1016/j.vetmic.2009.06.021

[3] Badia, X. and Lizán, L. (2003) Quality of life studies. In Martín, A. and Cano, J., Eds., Primary attention: Concepts, organization and clinic (In Spanish). Elsevier, Madrid, 39-81.

[4] Acha, N. P. and Szyfres, B. (2003) Zoonoses and communicable diseases common to man and animals. 3rd Edition, Vol. 1, Pan American Health Organization (PAHO), Washington DC.

[5] Schussler, J. M., Fenves, A. Z. and Sutker, W. L. (1997) Intermittent fever and pancytopenia in young Mexican man. Southern Medical Journal, 90, 1035-1037. doi:10.1097/00007611-199710000-00013

[6] Hernández, C. (2006) Rurality, search borders. The eastern part of the State of Tlaxcala. In Delgadillo, J., Ed., Territorial approach to rural development in Mexico (In Spanish). Multidisciplinary Research Center of National Autonomous University of Mexico and the Tlaxcala College, Mexico City.

[7] Kauffer, M. (2008) Public policies and commitments of the researcher. Public policy, some general notes (In Spanish).

www.ecosur.mx/ecofronteras/ecofrontera/ecofront16/pdf/ politicaspublicas

[8] Myrdal, G. (1968) Economic theory and underdeveloped regions (In Spanish). Ed. Fondo de Cultura Económica, México City, 22-32.

[9] Ware, J. E. and Gandek, B. (1998) Overview of the SF-36 health survey and the international quality of life assessment (IQOLA) project. Journal of Clinical Epidemiology, 51, 903-912. doi:10.1016/S0895-4356(98)00081-X

[10] INEGI (2011) National Institute of Statistics and Geography. Mexican Government (In Spanish). http://www.inegi.org.mx/inegi/default.aspx

[11] CONAPO and National Population Council (2005) Human development indices in Tlaxcala, Mexico. Federal Government of Mexico.

http://www.conapo.gob.mx/00cifras/proy/RM.xls 
[12] Ramírez, E. (2006) Regional analysis of goat production systems in the Eastern state of Tlaxcala (In Spanish). AMECIDER Congress, Yucatan, 28-30 October.

[13] INDRE (2006) Brucelosis. Progress and prospects. Technical publication of National Institute Diagnostic and Epidemiological Reference No 16. Health Department Epidemiology of Mexico (In Spanish). www.cenavece.salud.gob.mx/indre/interior/lab brucelosis $\underline{1 . h t m l}$

[14] Trivelli, C., Yancari, J. and De los Ríos, C. (2009) Crisis and rural poverty in Latin America (In Spanish). IEP Instituto de Estudios Peruanos 61 Perú.

[15] Yentzen, G. (2004) Quality of life profile in persons with chronically diseases. Health Questionnaire SF-36. The short-form-36. Health Survey. Health Promotion Division. School of Public Health. School of Medicine. U. de Chile (In Spanish). http://epi.minsal.c/cdvida/doc/Docgyentsen.ppt

[16] WHO/FAO/OIE (2004) Report of the WHO/FAO/OIE Joint Consultation on Emerging Zoonotic Disease, 3-5 May, Geneva. http://www.who.int/zoonoses/en

[17] Alonso, J., Prieto, L. and Antó, J. M. (1995) The Spanish version of SF-36 health survey (health questionnaire SF-36). An instrument for measuring clinical outcomes (In Spanish). Medical Clinic (Barcelona), 104, 771-776.

[18] Ayuso-Mateos, J. L., Lasa, L., Vázquez-Barquero, J. L., Oviedo, A. and Diez-Maneique, J. F. (1999) Measuring health status in psychiatric community surveys: Internal and external validity of the Spanish version of the SF-36. Acta Psychiatrica Scandinavica, 99, 26-32. doi:10.1111/j.1600-0447.1999tb

[19] Statistical Package for the Social Science (2007) SPSS for Windows [Computer program]. Version 15. Chicago.

[20] Eales, K. M., Norton, R. E. and Ketheesan, N. (2010) Short report: Brucellosis in Northern Australia. The Ame- rican Journal of Tropical Medicine and Hygiene, 83, 876878. doi:10.4269/ajtmh.2010.10-0237

[21] Perry, B., McDermott, J. and Randolph, T. (2001) Can epidemiology and economic make a meaningful contribution to national animal-disease control. Preventive Veterinary Medicine, 48, 231-260. doi:10.1016/S0167-5877(00)00203-8

[22] Martínez, H. (2007) Application and validation of the SF-36 to evaluate the quality of life in adult asthmatic patients with allergic rinitis (In Spanish). Ph.D. Thesis, National Autonomous University of Mexico, Mexico City.

[23] Galicia, S. (2008) Value of exacerbations with the physical capacity and quality of life in patients with chronic obstructive pulmonary disease. Ph.D. Thesis, National Autonomous University of Mexico, Mexico City.

[24] Siordia, Z. (2008) Determining the quality of life in androgenetic alopecia with the SF-36. Ph.D. Thesis, National University of Mexico. Dermatologic Center. Dr. Ladislao de la Pascua, México City.

[25] Ramírez, B. (1995) The region and its difference. The central valley of Queretaro 1940-1990. (1 $1^{\text {a }}$ Ed) UAMXochimilco, México, UAQ, National network in urban research (In Spanish), México City, 25-47.

[26] Ruiz, R. N. and Delgado, C. J. (2008) Territory and new rural areas: A theoretical course on the transformation of the rural-urban relationship (In Spanish). Eure, Santiago. doi:10.4067/S0250-71612008000200005

[27] McDevitt, D. G. (1973) Symptomatology of chronic brucellosis. British Journal of Industrial Medicine, 30, 385389.

[28] Castillo, A. (2008) Quality of life related to health in people with chronic degenerative diseases (In Spanish). Revista Cubana de Investigación Biomedica, 27, 3-4. 